\title{
Halitose: uma condição multifatorial que tem tratamento
}

\author{
Halitosis: a multifactorial condition that has treatment
}

Halitosis: una condición multifactorial que tiene tratamiento

\begin{abstract}
Hervaine de Fátima Cayres Borges ${ }^{1 *}$, Lívia Fernanda Prado Santiago ${ }^{1}$, Karen da Silva Soares Santos ${ }^{1}$, Tarcielly Fernanda Nascimento da Silva ${ }^{1}$, Izabel Cristina Gomes de Mendonça ${ }^{1}$, Marcos Moura ${ }^{2}$
\end{abstract}

\section{RESUMO}

Objetivo: Contextualizar as principais causas e consequências psicossociais decorrentes da halitose e transmitir a importância do correto diagnóstico pelo cirurgião-dentista para direcionar o portador da patologia para o tratamento mais adequado. Métodos: Trata-se de uma revisão de literatura onde foram analisados artigos publicados em periódicos ou em bases de dados eletrônicas (PubMed Mesh, portal de periódicos CAPES, EBSCO, DeCS e Google Acadêmico) e livros de acervo bibliográfico utilizando os seguintes descritores: bactérias anaeróbias, diagnóstico etiologia, halitose e higiene bucal. Resultados: A halitose, comumente conhecida por mau hálito, é uma condição multifatorial bastante frequente na população que sinaliza a presença de um desequilíbrio no organismo que precisa ser diagnosticado e tratado. Sua etiologia mais comum é a má higiene bucal e alteração dos padrões salivares, mas pode estar relacionada a patologias associadas ao sistema digestivo ou respiratório e fatores sistêmicos, como a diabetes. Surpreendentemente, este tema tem sido negligenciado por profissionais das diversas áreas de saúde, visando apenas o cirurgião-dentista como principal responsável pelo diagnóstico e tratamento da halitose. Conclusão: É fundamental e imprescindível que tanto o cirurgião-dentista quanto os demais profissionais da área da saúde se informem e estejam aptos sobre a proveniência multifatorial da halitose, para providenciar o diagnóstico correto e direcionar o paciente a um tratamento adequado para um prognóstico de sucesso.

Palavras-chave: Diagnóstico, Etiologia, Halitose, Higiene Bucal.

\begin{abstract}
Objective: To contextualize the main causes and psychosocial consequences of halitosis and to transmit the importance of correct diagnosis by the dental surgeon to direct the patient of the pathology to the most appropriate treatment. Methods: This is a literature review where articles published in journals or in electronic databases (PubMed Mesh, CAPES, EBSCO, DeCS and Google Scholar) were analyzed and bibliographic books using the following descriptors: bacteria anaerobic, diagnostic etiology, halitosis and oral hygiene. Results: Halitosis, commonly known as bad breath, is a very frequent multifactorial condition in the population that signals the presence of an imbalance in the body that needs to be diagnosed and treated. Its most common etiology is poor oral hygiene and alteration of salivary patterns but may be related to pathologies associated with the digestive or respiratory system and systemic factors, such as diabetes. Surprisingly, this issue has been neglected by professionals from different health areas, aiming only at the dental surgeon as the main responsible for the diagnosis and treatment of halitosis. Conclusion: It is fundamental and essential that both the dental surgeon and other health professionals inform and be apt about the multifactorial provenance of halitosis, to provide the correct diagnosis and to direct the patient to an appropriate treatment for a successful prognosis.
\end{abstract}

Key words: Diagnosis, Etiology, Halitosis, Oral Hygiene.

${ }^{1}$ Centro Universitário Cesmac em Maceió-AL. *E-mail: hervaine@hotmail.com

${ }^{2}$ Membro da Associação Brasileira de Halitose.

SUBMETIDO EM: 5/2018

ACEITO EM: 6/2018

PUBLICADO EM: 12/2018

REAS/EJCH | Vol.Sup.18 | e82 | DOI: https://doi.org/10.25248/reas.e82.2019 Página 1 de 7 


\section{RESUMEN}

Objetivo: Contextualizar las principales causas y consecuencias psicosociales derivadas de la halitosis y transmitir la importancia del correcto diagnóstico por el cirujano-dentista para dirigir al portador de la patología para el tratamiento más adecuado. Métodos: En el presente trabajo se analizaron los resultados obtenidos en el análisis de los resultados obtenidos en el análisis de los resultados obtenidos en el estudio. anaerobio, diagnóstico etiología, halitosis e higiene bucal. Resultados: La halitosis, comúnmente conocida por mal aliento, es una condición multifactorial bastante frecuente en la población que señala la presencia de un desequilibrio en el organismo que necesita ser diagnosticado y tratado. Su etiología más común es la mala higiene bucal y alteración de los patrones salivales, pero puede estar relacionada a patologías asociadas al sistema digestivo o respiratorio y factores sistémicos, como la diabetes. Es sorprendente que este tema ha sido descuidado por profesionales de las diversas áreas de salud, visando sólo al cirujano-dentista como principal responsable del diagnóstico y tratamiento de la halitosis. Conclusión: Es fundamental e imprescindible que tanto el cirujanodentista como los demás profesionales del área de la salud se informen y estén aptos sobre la procedencia multifactorial de la halitosis, para proporcionar el diagnóstico correcto y dirigir al paciente a un tratamiento adecuado para un pronóstico de éxito.

Palabras clave: Diagnóstico, Etiología, La halitosis, Higiene bucal.

\section{INTRODUÇÃO}

A halitose, mais conhecida como "mau hálito", apresenta-se com causa multifatorial determinada por possuir odores indesejáveis oriundos principalmente da cavidade bucal, independentemente de sua etiologia estar associada a fatores intra ou extra orais (CARVALHO, 2016).

Em geral, os fatores mais comuns passíveis de desencadear a halitose podem ser de origem fisiológica, local, sistêmica ou patológica (BUTZE et al., 2015). O mau hálito não é uma doença, mas, comumente é considerado um sinal de que existe alguma desordem no organismo (DUTRA, 2006).

A halitose pode ser desencadeada por diversos fatores sistêmicos, como exemplo, podemos citar a diabetes, doenças respiratórias e do sistema digestivo, porém, aproximadamente $90 \%$ dos casos de halitose são provenientes da cavidade bucal e estão relacionados à higiene deficiente do seu portador. Em especial, a má higienização da língua pode ser fator primordial para desencadear o problema (DUTRA, 2006).

A língua é formada por estruturas papilares e, consequentemente, seus sulcos são os maiores retentores bacterianos da boca. Ainda, a língua está propensa a aderir um material composto viscoso, amarelado ou esbranquiçado em seu dorso: a saburra lingual. Por esse motivo, a halitose consegue instalar-se com facilidade e se torna um pouco difícil de tratar (DUTRA, 2006; AMADO et al., 2010).

A saburra lingual é reproduzida com o auxílio do acúmulo de diferentes microorganismos, da descamação celular e dos restos alimentares. Comumente, está aderida na região posterior de língua, mas pode ser encontrada por todo o dorso (DUTRA, 2006; AMADO et al., 2010).

Os componentes do biofilme formado na cavidade oral são os principais causadores do mau hálito (BUTZE et al., 2015), a partir do momento em que são degradados pela ação de bactérias gram negativas anaeróbicas, onde os principais protagonistas são: Porphyromonas gingivalis, Fusobacterium nucleatum, Treponema denticola, Prevotella intermédia e Bacteroides forsythus (AMADO et al.,2010; ULIANA, BRIQUES, 2003).

A degradação da matéria orgânica por microorganismos é responsável pela produção de metabólitos sulfídricos - os compostos sulfurados voláteis (CSV), que são liberados através do processo de proteólise com a exalação destes. Os principais CSVs são o sulfeto de hidrogênio, metilmercaptana e dimetilsulfeto (BUTZE et al., 2015; ULIANA, BRIQUES, 2003).

É fundamental que uma investigação minuciosa seja realizada para concluir um correto diagnóstico e iniciar o tratamento das causas do problema com um prognóstico favorável, tanto por motivos de saúde física e psicológica, quanto por questões relacionadas diretamente a interação social (CARVALHO, 2016; ULIANA, BRIQUES, 2003). 
É importante levar em consideração que esta condição pode resultar em comportamentos distintos como ansiedade, tristeza, depressão, comportamentos antissociais e neuroses, por exemplo, podendo progredir para atitudes autodestrutivas, como tentativas de suicídio (CARVALHO, 2016; ULIANA, BRIQUES, 2003).

Este trabalho tem por objetivo ressaltar a importância da determinação de um correto diagnóstico das causas da halitose, indicando seus fatores e consequências psicológicas e sociais para os indivíduos que sofrem com o problema e consequente tratamento para todos os profissionais da área de saúde.

\section{MÉTODO}

Esta pesquisa constitui-se de uma revisão de literatura que foi realizada entre o período de agosto de 2017 a março de 2018, onde foram analisados artigos publicados em bases de dados eletrônicos (Pubmed, Mesh, portal de periódicos CAPES, EBSCO, DeCS, e Google Acadêmico) e livros nos acervos bibliográficos presentes na biblioteca central do Centro Universitário Cesmac.

Foram consultados textos em língua portuguesa, inglesa e espanhola, que se referiram à halitose (mau hálito), saburra ou biofilme lingual e fluxo salivar, tendo como critérios de exclusão o período de publicações das obras acadêmicas, sendo selecionados os textos a partir do ano 2000 até os dias atuais, verificando a presença de mudanças e avanços no estudo da halitose a partir dos seguintes termos de busca: "Higiene Bucal", "Halitose", "Etiologia de Halitose" e "Diagnóstico de Halitose".

\section{RESULTADOS E DISCUSSÃO}

Halitose, palavra oriunda do latim: "halitus", que significa ar aspirado, com o sufixo "ose", complementando uma alteração patológica, define-se como uma condição ou alteração do hálito (BUTZE et al., 2015; SANTANA et al., 2006).

O hálito é formado pelo ar expirado posteriormente ao processo de hematose, que são trocas gasosas fisiológicas em conjunto com algumas substâncias. Estas substâncias se deslocam do intestino e se dirigem para o fígado, (onde ocorrem as sínteses proteicas, lipídicas e de carboidratos), bile, sangue e por fim para os pulmões, quando são expirados (ULIANA, BRIQUES, 2003; ALBUQUERQUE et al., 2004).

Popularmente conhecida como mau hálito, fedor da boca ou ainda hálito fétido, a halitose é uma condição multifatorial caracterizada por odores desagradáveis provenientes da cavidade bucal exalado na expiração, independentemente do fator etiológico intra ou extra oral (CARVALHO, 2016; DAL RIO et al., 2007; CONCEIÇÃO et al., 2014; PASSARELLI, GURFINKEL, 2014).

Os estudos percussores em halitose surgiram na década de 70 com intenção de esclarecer suas origens e possíveis terapias para seu tratamento, tendo em vista a questão de que o mau hálito é uma condição que afeta grande parte da população há diversas gerações (SANTANA et al., 2006). Assim, através do estudo, foram constatados que os fatores etiológicos que resultam em halitose podem ser de origem fisiológica, local ou de razões sistêmicas ou patológicas (BUTZE et al., 2015; AMADO et al., 2010).

Diferente do que comumente se acredita, o mau hálito não é considerado uma doença, mas, uma condição afetada por diversos fatores interdependentes como o fluxo salivar, a flora bacteriana gramnegativa, o pH alcalino na cavidade bucal e presença de resíduos celulares e alimentares (DAL RIO et al., 2007; CONCEIÇÃO et al., 2014; PASSARELLI, GURFINKEL, 2014).

Essa condição pode variar consideravelmente de acordo com a hora do dia, idade e até ser relacionado aos hábitos alimentares e longos períodos de jejum, o mau hálito também está associado ao sinal de que algo no organismo está desequilibrado (DAL RIO et al., 2007; CONCEIÇÃO et al., 2014; PASSARELLI, GURFINKEL, 2014).

Para o desenvolvimento do estudo, houve o levantamento de 22 artigos, sendo 8 excluídos pelo fato das informações terem um período superior a 10 anos, e inclusos 14 artigos com relevância. Abaixo se encontra um Quadro 1 com os principais dados das obras encontradas: 
Quadro 1 - Principais informações dos artigos

\begin{tabular}{|c|c|c|c|}
\hline Autores & Titulo & $\begin{array}{l}\text { Revista/Ano de } \\
\text { Publicação }\end{array}$ & Principal Objetivo \\
\hline $\begin{array}{l}\text { ALBUQUERQUE } \\
\text { JAP et al. }\end{array}$ & $\begin{array}{c}\text { A importância do } \\
\text { Cirurgião-Dentista na } \\
\text { prevenção, diagnóstico e } \\
\text { tratamento da halitose }\end{array}$ & $\begin{array}{l}\text { Odontologia } \\
\text { Clínico-Científica/ } \\
2004\end{array}$ & $\begin{array}{l}\text { O autor apresenta uma revisão da literatura } \\
\text { sobre halitose enfocando os aspectos } \\
\text { relacionados com etiologia, diagnóstico, } \\
\text { prevenção e tratamento. }\end{array}$ \\
\hline AMADO FM et al & $\begin{array}{l}\text { Halitose: métodos de } \\
\text { avaliação e tratamento }\end{array}$ & $\begin{array}{c}\text { Revista Int. de } \\
\text { Estomatopatologia/ } \\
2010 \\
\end{array}$ & $\begin{array}{l}\text { O autor relata os principais métodos de } \\
\text { avaliação do hálito, suas limitações e } \\
\text { vantagens, e principais formas de tratamento. }\end{array}$ \\
\hline BUTZE JP et al & $\begin{array}{l}\text { Perspectivas atuais sobre } \\
\text { halitose bucal: revisão de } \\
\text { literatura }\end{array}$ & $\begin{array}{l}\text { Brazilian Journal of } \\
\text { Periodontology/ } \\
2015\end{array}$ & $\begin{array}{l}\text { Levantar e fornecer informações que possam } \\
\text { auxiliar o dia-a-dia do cirurgião-dentista na } \\
\text { busca por métodos que facilitem o diagnóstico } \\
\text { da halitose e que, concomitantemente, } \\
\text { conduzam a um adequado manejo terapêutico. }\end{array}$ \\
\hline CALIL CM et al & $\begin{array}{l}\text { Qual é a origem do mau- } \\
\text { hálito? }\end{array}$ & $\begin{array}{l}\text { Ver. de Odontologia } \\
\text { da UNESP/ } 2006\end{array}$ & $\begin{array}{l}\text { Auxiliar os cirurgiões-dentistas no manejo de } \\
\text { pacientes sob essa condição, além de informar } \\
\text { os profissionais de saúde em geral. }\end{array}$ \\
\hline $\begin{array}{l}\text { CARVALHO } \\
\text { AAT et al }\end{array}$ & Halitose: mitos e verdades & Ver. Saúde/ 2001 & $\begin{array}{l}\text { Suas eventuais causas, meios de diagnostico, } \\
\text { além de possíveis tratamentos, alertando o } \\
\text { cirurgião-dentista sobre sua fundamental } \\
\text { importância. }\end{array}$ \\
\hline $\begin{array}{l}\text { CARVALHO } \\
\text { DFC }\end{array}$ & $\begin{array}{l}\text { Prevalência do mau hálito } \\
\text { na consulta de } \\
\text { periodontologia na clínica } \\
\text { da FMDUP [monografia] }\end{array}$ & $\begin{array}{l}\text { Faculdade de } \\
\text { Medicina Dentária - } \\
\text { Univ. do Porto/ } \\
2016\end{array}$ & $\begin{array}{l}\text { Pretendeu-se avaliar a prevalência do mau } \\
\text { hálito em pacientes saudáveis ou com doença } \\
\text { periodontal na consulta de Periodontologia na } \\
\text { clínica da Faculdade Medicina Dentária da } \\
\text { Universidade do Porto, através da medição da } \\
\text { halitose pelo método organolético. }\end{array}$ \\
\hline $\begin{array}{l}\text { CONCEIÇÃO } \\
\text { MD et al }\end{array}$ & $\begin{array}{l}\text { Perfil psicopatológico e } \\
\text { alterações } \\
\text { comportamentais em } \\
\text { pacientes com queixa de } \\
\text { halitose: uma revisão } \\
\end{array}$ & $\begin{array}{l}\text { Rev. da Assoc. } \\
\text { Paulista de } \\
\text { Cirurgiões- } \\
\text { Dentistas/2014 }\end{array}$ & $\begin{array}{l}\text { Avaliar, através de uma revisão da literatura, } \\
\text { dois aspectos importantes no tratamento do } \\
\text { mau hálito: perfil psicopatológico e alterações } \\
\text { comportamentais em pacientes com queixa em } \\
\text { ter halitose }\end{array}$ \\
\hline $\begin{array}{l}\text { DAL RIO ACC } \\
\text { et al }\end{array}$ & $\begin{array}{l}\text { Halitose: proposta de um } \\
\text { protocolo de avaliação. }\end{array}$ & $\begin{array}{l}\text { Rev. Bra. de } \\
\text { Otorrinolaringologia/ } \\
2007\end{array}$ & $\begin{array}{l}\text { Elaborar um protocolo de avaliação da halitose } \\
\text { com o objetivo de minimizar custos, evitar } \\
\text { exames desnecessários e orientar o } \\
\text { diagnóstico causal. }\end{array}$ \\
\hline DUTRA EP & $\begin{array}{l}\text { A saburra lingual como } \\
\text { fator de risco para a } \\
\text { doença periodontal } \\
\text { [monografia }\end{array}$ & $\begin{array}{l}\text { Centro de Estudos } \\
\text { Odontológicos São } \\
\text { Leopoldo Mandic/ } \\
2006\end{array}$ & $\begin{array}{l}\text { Analisar a presença ou ausência da saburra } \\
\text { lingual em pacientes portadores de doença } \\
\text { periodontal. }\end{array}$ \\
\hline GUERRA CM & $\begin{array}{l}\text { Análise de alteração dos } \\
\text { níveis de compostos } \\
\text { sulfurados voláteis no } \\
\text { hálito por meio de dois } \\
\text { protocolos de higiene } \\
\text { bucal [dissertação] }\end{array}$ & $\begin{array}{l}\text { São Paulo: } \\
\text { Universidade de } \\
\text { Guarulhos/ } 2012\end{array}$ & $\begin{array}{l}\text { Avaliar a eficácia de dois regimes de higiene } \\
\text { bucal em alterar os níveis de compostos } \\
\text { sulfurados voláteis (CSV) no hálito e as } \\
\text { proporções dos microrganismos bucais. }\end{array}$ \\
\hline OLINDA T & $\begin{array}{l}\text { Halitose: um desafio que } \\
\text { tem cura }\end{array}$ & Editora Plena/ 2003 & $\begin{array}{l}\text { Estabelecer a sua importância dentro de uma } \\
\text { perspectiva histórica e realça os meios } \\
\text { utilizados para a sua determinação e focaliza } \\
\text { as suas causas. }\end{array}$ \\
\hline $\begin{array}{l}\text { PASSARELLI N } \\
\text { et al }\end{array}$ & Halitose & $\begin{array}{l}\text { Jornal Brasileiro de } \\
\text { Medicina/1981 }\end{array}$ & Principais origens e tratamento \\
\hline $\begin{array}{l}\text { SANTANA NN } \\
\text { et al }\end{array}$ & $\begin{array}{l}\text { Halitose: abra a boca sem } \\
\text { receio }\end{array}$ & $\begin{array}{l}\text { Arquivos de } \\
\text { Ciências da Saúde } \\
\text { da Unipar/ 2006; }\end{array}$ & $\begin{array}{l}\text { Auxiliar o profissional no esclarecimento da } \\
\text { halitose, para que este possa realizar um } \\
\text { correto diagnóstico e tratamento, contribuindo } \\
\text { assim para uma melhora no convívio social de } \\
\text { seus pacientes }\end{array}$ \\
\hline $\begin{array}{l}\text { ULIANA RMB, } \\
\text { BRIQUES W }\end{array}$ & $\begin{array}{l}\text { Halitose: conceitos básicos } \\
\text { sobre diagnóstico, } \\
\text { microbiologia, causas e } \\
\text { tratamento. }\end{array}$ & $\begin{array}{c}\text { Anais do } 15^{\circ} \\
\text { Conclave } \\
\text { Odontológico Inter } \\
\text { de Campinas/ } 2003\end{array}$ & $\begin{array}{l}\text { Principais causas da halitose, diagnóstico e } \\
\text { fundamentos de tratamento }\end{array}$ \\
\hline
\end{tabular}

Fonte: Autores, 2018. 


\section{Halitose de origem fisiológica}

Com odor desagradável, a halitose fisiológica é transitória e é decorrente nos períodos posteriores a horas seguidas do sono e jejum prolongado, também conhecida como mau hálito matinal. Com o fluxo salivar reduzido, descamação de células epiteliais e a putrefação de restos alimentares, que são aglomerados durante esses períodos inertes. (DAL RIO et al., 2007; CONCEIÇÃO et al., 2014; PASSARELLI, GURFINKEL, 2014).

$\mathrm{Na}$ presença do jejum, uma leve hipoglicemia pode ser constatada, tornando o problema mais acentuado em indivíduos desidratados, com maus hábitos higiênicos e respiradores bucais, possibilitando a proliferação de microorganismos (DAL RIO et al., 2007; CONCEIÇÃO et al., 2014; PASSARELLI, GURFINKEL, 2014).

A halitose fisiológica desaparece ao acordar após a ingestão de alimentos, higienização da cavidade oral e o reestabelecimento do fluxo salivar, considerado o detergente bucal (BUTZE et al., 2015; ALBUQUERQUE et al., 2004; CALIL et al., 2006).

\section{Halitose de origem local}

Os fatores locais são os principais causadores do mau hálito, dentre eles, as lesões cariosas e suas implicações, a microbiota bucal, os elementos protéticos e aparelhos ortodônticos, gengivites, periodontopatias, pericoronarites, retenção de sangue nos interstícios dentários, língua fissurada, modificação na composição da saliva, e a saburra ou biofilme lingual são os principais determinantes da halitose na cavidade bucal (ALBUQUERQUE et al., 2004; CARVALHO et al., 2001).

Em especial, a língua é formada por estruturas papilares e seus sulcos são os maiores retentores bacterianos da boca. O acúmulo de microorganismos, a descamação celular, a presença de leucócitos mortos e restos alimentares compõem a saburra lingual (AMADO et al., 2010), caracterizada por ser composta de material viscoso, amarelado ou esbranquiçado, aderido ao dorso da língua e agrupado principalmente na região posterior (DUTRA, 2006).

Com a redução do fluxo salivar, a produção de mucina em conjunto com o aumento da descamação celular, e a decomposição orgânica de restos alimentares temos nesses fatores as principais causas da saburra/biofilme lingual. Além de fatores fisiológicos, há produção de saburra lingual por motivos traumáticos e também por razões sistêmicas. (AMADO et al., 2010).

O aumento na produção de mucina em decorrência do reduzido fluxo salivar é resultante de fatores fisiológicos (sono, jejum), baixa ingestão de líquido, desidratação, radioterapia, quimioterapia, estresse, doenças sistêmicas, e o uso de medicamentos que provocam xerostomia (ALBUQUERQUE et al., 2004; OLINDA, 2003).

Por outro lado, o aumento da descamação celular, por razões traumáticas e sistêmicas, é consequente de alguns fatores como: respiração bucal, uso de fumo e drogas, aftas, mordiscamento da mucosa oral e comissura labial, uso de colutórios com alto teor alcoólico, alterações hormonais da menstruação e menopausa, deficiência de vitamina D e A e dentre outros (ALBUQUERQUE et al., 2004; OLINDA, 2003).

Além dos fatores citados anteriormente, segundo Tarzia (2010), há a formação do biofilme lingual por predisposição morfológica da língua, com a altura das papilas gustativas, fissura e posicionamento da língua, e o fator predisponente por condições comportamentais, tais como: falar em excesso ou ficar muito tempo calado.

Devido a colônia de bactérias conjuntamente com restos alimentares e restos orgânicos provenientes da cavidade oral temos os principais causadores do mau odor instaurado na cavidade bucal, quando esta composição se adere ao dorso da língua. (DUTRA, 2006). Os componentes que formam o biofilme são degradados pela ação de bactérias gram-negativas anaeróbicas e possuem como principais protagonistas: Porphyromonas gingivalis, Fusobacterium nucleatum, Treponema denticola, Prevotella intermedia $e$ Bacteroides forsythus (AMADO et al., 2010; ULIANA, BRIQUES, 2003). 
A degradação de restos alimentares e de células descamadas pelos microorganismos presentes são ocasionadas pela ação metabólica proteolítica que desencadeia uma reação bioquímica (BUTZE et al., 2015; ULIANA, BRIQUES, 2003; OLINDA, 2003).

A consequência desse processo é a produção e liberação de gases derivados do enxofre e compostos sulfídricos ou sulfurados voláteis (CSV). Os principais compostos sulfurados voláteis são: o sulfeto de hidrogênio $\left(\mathrm{H}_{2} \mathrm{~S}\right)$, metilmercaptana $\left(\mathrm{CH}_{3} \mathrm{SH}\right)$ e dimetilsulfeto $\left[\left(\mathrm{CH}_{3}\right)_{2} \mathrm{~S}\right]$, que são responsáveis por provocar o mau hálito, precursores do mau hálito (BUTZE et al., 2015; ULIANA, BRIQUES, 2003; OLINDA, 2003; GUERRA, 2012).

\section{Halitose de origem sistêmica ou patológica}

Quando a halitose se torna intensa e persistente, pode indicar desordens na cavidade bucal como doença periodontal, gengivite ou acúmulo de biofilme lingual, que podem ser indicativos de origem sistêmica como: diabetes mellitus, cirrose hepática, úlceras gastrointestinais, hemorragia interna, leucemia, uremia, infecção sinusal ou neoplasia no trato respiratório (CALIL et al., 2006).

A halitose patológica apresenta características peculiares e é de difícil controle, portanto, maus odores devem ser corretamente diagnosticados e rapidamente tratados. Para tanto, uma anamnese minuciosa deve ser realizada assim como detalhados exames clínicos, devendo-se sempre orientar o portador sobre dietas e tratamentos de patologias sistêmicas pertinentes aos sintomas do mau hálito (CARVALHO et al., 2001).

\section{Impacto social causado pela halitose}

Na maioria dos casos o portador do mau odor acaba se excluindo do convívio social ou o limitando e as pessoas que convivem com este indivíduo evitam o seu contato. Para as duas partes, portador e não portador, a situação se torna muito incômoda e desagradável (DAL RIO et al., 2007; CONCEIÇÃO et al., 2014; PASSARELLI, GURFINKEL, 2014).

O impacto social produzido pela halitose causa situações constrangedoras que afetam a qualidade de vida do indivíduo como um todo que, em alguns casos, desenvolve psicopatias inerentes à sua condição. Dessa maneira, é fundamental que uma investigação minuciosa seja realizada para um correto diagnóstico e tratamento das causas da halitose venha com um prognóstico favorável (CARVALHO, 2016; ULIANA, BRIQUES, 2003; OLINDA, 2003; CONCEIÇÃO et al., 2014).

O tratamento do mau hálito baseado nos aspectos psicopatológicos, assim como em alterações de comportamento dos pacientes são essenciais para serem melhores explorados e compreendidos. Para os casos resistentes, em que os pacientes se mostram inseguros, há sugestão de encaminhamento para psicólogos e/ou psiquiatras planejando um tratamento multiprofissional (CONCEIÇÃO et al., 2014).

\section{Diagnóstico e tratamento}

O diagnóstico pode ser realizado através de uma anamnese criteriosa e um minucioso exame clínico em busca dos possíveis fatores que contribuíram para o estabelecimento da condição (CARVALHO, 2016; ULIANA, BRIQUES, 2003; ALBUQUERQUE et al., 2004; DAL RIO et al., 2007).

Felizmente, a maioria dos casos de halitose é oriunda de problemas de origem bucal, o que torna o Cirurgião-Dentista o profissional mais habilitado para seu diagnóstico e posterior tratamento, respeitando as singularidades de cada paciente (DUTRA, 2006; CONCEIÇÃO et al., 2014).

Segundo Dutra (2006), há uma média de que $90 \%$ dos casos indicam que a etiologia da halitose possa ser proveniente da cavidade oral (de origem local), pertinente a uma higiene inadequada do seu portador, sendo que $8 \%$ são relacionadas as doenças respiratórias e otorrinolaringológicas, e apenas $2 \%$ dos casos estão ligados as doenças do sistema digestivo e outras razões (DAL RIO et al., 2007).

O tratamento, visa combater as possíveis causas encontradas com um caráter multidisciplinar. Se o mau hálito for diagnosticado por origem bucal, este deve ser tratado com higiene bucal adequada e frequente 
(escovação, uso de fio dental e uso do limpador de língua). Se a origem da halitose for de causas sistêmicas, o paciente deve ser encaminhado a um profissional mais indicado para que ele possa intervir e estabelecer uma terapia eficaz (ULIANA, BRIQUES, 2003; ALBUQUERQUE et al., 2004; CONCEIÇÃO et al., 2014).

\section{Importância do cirurgião-dentista}

Ao identificar que a halitose é, de fato, um problema de saúde pública, é necessário considerar a grande massa populacional portadora desta condição. Sendo o diagnóstico difícil e havendo uma restrita fonte literária neste campo, esse trabalho ressalta a importância do cirurgião-dentista e demais profissionais para uma abordagem interdisciplinar (DAL RIO et al., 2007; PASSARELLI, GURFINKEL, 2014).

A halitose é considerada uma condição multifatorial e multidisciplinar que requere uma maior atenção e posterior comunicação entre os profissionais das diversas áreas da saúde (ULIANA, BRIQUES, 2003).

Como o cirurgião-dentista é o profissional que mais tem familiaridade com a boca, é de grande importância que este exerça procedimentos preventivos como instruções de higiene oral e a manutenção da saúde bucal, por exemplo (ALBUQUERQUE et al., 2004).

É importante que o dentista seja o primeiro profissional a avaliar pacientes com halitose para tratar causas de fatores locais, se existentes. Mas, se a suspeita não for de origem bucal, é possível que seja necessária uma intervenção médica (CARVALHO et al., 2001).

\section{CONSIDERAÇÕES FINAIS}

A halitose ainda é um problema muito discutido, mas, pouco tratado. Em alguns casos, apenas as instruções de higienização bucal não bastam e, muitas vezes, a interdisciplinaridade pode falhar.

É importante enfatizar, também, que os trabalhos publicados nesta temática ainda são bastante reduzidos. A necessidade da informação para o público acadêmico e a atualização do cirurgião-dentista são indispensáveis para um diagnóstico apropriado, a fim de resultar em um tratamento adequado e eficiente para os pacientes portadores do mau hálito.

\section{REFERÊNCIAS}

1. ALBUQUERQUE JAP, SANTOS AA, GONÇALVES SRJ et al. A importância do Cirurgião-Dentista na prevenção, diagnóstico e tratamento da halitose. Odontologia Clínico-Científica, 2004; 3(3): 169-172.

2. AMADO FM, CHINELLATO LEM, TARZIA O. Halitose: métodos de avaliação e tratamento. Revista Internacional de Estomatopatologia, 2010; 2(4): 30-35.

3. BUTZE JP, ANGST PDM, GOMES SC. Perspectivas atuais sobre halitose bucal: revisão de literatura. Brazilian Journal of Periodontology, 2015; 25(2): 48-54.

4. CALIL CM, OLINDA T, MARCONDES FK. Qual é a origem do mau-hálito?. Revista de Odontologia da UNESP, 2006; 35(3): 185190.

5. CARVALHO AAT, SAMPAIO MCC, SOUZA R et al. Halitose: mitos e verdades. Revista Saúde, 2001; 15(1): 27-33.

6. CARVALHO DFC. Prevalência do mau hálito na consulta de periodontologia na clínica da FMDUP [monografia]. Porto: Faculdade de Medicina Dentária - Universidade do Porto; 2016.

7. CONCEIÇÃO MD, GIUDICE FS, MAROCCHIO LS. Perfil psicopatológico e alterações comportamentais em pacientes com queixa de halitose: uma revisão. Revista da Associação Paulista de Cirurgiões-Dentistas, 2014; 68(1): 14-21.

8. DAL RIO ACC, NICOLA EMD, TEIXEIRA ARF. Halitose: proposta de um protocolo de avaliação. Revista Brasileira de Otorrinolaringologia, 2007; 73(6): 835-842.

9. DUTRA EP. A saburra lingual como fator de risco para a doença periodontal [monografia]. São Paulo: Centro de Estudos Odontológicos São Leopoldo Mandic; 2006.

10. GUERRA CM. Análise de alteração dos níveis de compostos sulfurados voláteis no hálito por meio de dois protocolos de higiene bucal [dissertação]. São Paulo: Universidade de Guarulhos; 2012.

11. OLINDA T. Halitose: um desafio que tem cura. 1.ed. Rio de Janeiro: Editora Plena, 2003.

12. PASSARELLI N, GURFINKEL S. Halitose. Jornal Brasileiro de Medicina, 1981; 8(9): 17-24

13. SANTANA NN, ALMEIDA SC, TOMAZINHO LF. Halitose: abra a boca sem receio. Arquivos de Ciências da Saúde da Unipar, 2006; 10(20): 169-172.

14. ULIANA RMB, BRIQUES W. Halitose: conceitos básicos sobre, diagnóstico, microbiologia, causas e tratamento. In: Anais do 15은 Conclave Odontológico Internacional de Campinas, maio 22-24, Campinas-SP; 2003. P. 1678-1699 